\title{
The Effect of Spinal Anaesthesia on Penile Tumescence
}

\author{
Sotonye Fyneface-Ogan ${ }^{1, \text { *, Ngozi Onyeanunam Ekeke }}{ }^{2}$ \\ ${ }^{1}$ Department of Anaesthesia, University of Port Harcourt Teaching Hospital, Port Harcourt, Nigeria \\ ${ }^{2}$ Department of Surgery, University of Port Harcourt Teaching Hospital, Port Harcourt, Nigeria
}

Email address:

sfyneface.ogan@gmail.com (S. Fyneface-Ogan)

*Corresponding author

\section{To cite this article:}

Sotonye Fyneface-Ogan, Ngozi Onyeanunam Ekeke. The Effect of Spinal Anaesthesia on Penile Tumescence. Journal of Anesthesiology. Vol. 6, No. 1, 2018, pp. 40-44. doi: 10.11648/j.ja.20180601.17

Received: June 19, 2018; Accepted: July 3, 2018; Published: July 30, 2018

\begin{abstract}
It is a common observation that following spinal anaesthesia, the penis usually elongates. The aim of this study was to determine the degree of change in penile length following spinal anaesthesia. Consecutive urosurgical patients undergoing spinal anaesthesia were recruited for this study. Those who received general anaesthesia or incomplete spinal blocked were also excluded. The flaccid length of the penis was measured before and after the administration of spinal anaesthesia. Penile length 15 minutes post-spinal anaesthesia was measured and recorded. The change in length was tested for statistical significant difference, the age of patient; diagnosis and type of surgery were also recorded. Forty three patients completed the study. Benign prostatic hypertrophy constituted $41.9 \%$ of the surgical indications. While $53.5 \%$ of the patients were ASA I, 39.5\% and $7.0 \%$ of them were ASA II and III respectively. While the mean initial penile length was $12.1 \pm 0.53$ $\mathrm{cm}$ and the mean final length was $15.7 \pm 0.53 \mathrm{~cm}$, the mean maximal change in penile length was $3.6 \pm 1.5 \mathrm{~cm} ; \mathrm{p}<0.0001$. There was no statistical correlation between age and mean differential change in length of penis $(r=-0.2842, p=0.43)$. It was therefore concluded that there was a significant change in penile length (tumescence) following successful spinal anaesthesia.
\end{abstract}

Keywords: Spinal Anaesthesia, Flaccid, Penile Length, Tumescence, Urologic Surgery

\section{Introduction}

Intraoperative penile tumescence is very frequent in males undergoing surgical procedures under regional anaesthesia. This change in penile length can pose a challenge to the attending urologist. The aetiology of tumescence following spinal anaesthesia is still nebulous. It is frequently thought that mechanism of tumescence involves the arterioles, venules, and arterovenous anastomotic channels of the corpora cavernosa. $[1,2]$ In the flaccid state, the arterioles are partially closed while the venules and arteriovenous channels remain open, providing an unimpeded drainage of the arterial inflow.

However, penile engorgement can result in partial or total tumescence at the time of both urologic and non-urologic surgeries. It could be challenging to perform the some urologic procedures especially transurethral resection of the prostate (TURP) during penile erection as this could render the urethroscope an inappropriate length for the erected penis and other complications such as excessive bleeding and urethral trauma could arise and surgery has to be delayed until successful detumescence or rescheduled to a later date.

The term 'tumescence' may be appropriately used in this index study to describe this phenomenon of painless penile erection during anaesthesia as this is usually short lived. Unlike priapism which could be defined as a persistent painful penile erection unaccompanied by desire or sexual excitement and/or arousal. It is well-known that priapism sustained for a long time (usually more than 4 hours) may result in oedema, increased risk of abrasion, tissue drying, and necrosis of the penis, with the prognosis, in general, depending on the type of priapism and the amount of time elapsed before the therapeutic intervention.

The aim of this study was determine the degree of change in penile length frequently observed in our routine urologic surgeries and compare its relationship with age of the adult males. 


\section{Patients and Methods}

Following approval from the hospital's ethics Committee and obtaining informed consent, all consecutive male patients scheduled for urologic surgeries were recruited for the study. Patients within the American Society of Anesthesiologists (ASA) physical status Class I and III were included. Men with history of penile and/or testicular pathology (e.g., Peyronie's disease or penile curvature), haemoglobin disorders (HbSS, HbSC, etc.) in-dwelling catheter, those requiring general anaesthesia and others with intercurrent diseases were excluded from the study.

Intravenous ranitidine $50 \mathrm{mg}$ was administered to all the participants in the morning 2 hours before surgery. On arrival to theatre, routine anaesthetic machine check was carried out, appropriate sized laryngoscope blade; tracheal tubes and laryngeal mask airway were made available. Monitors were applied and baseline vital signs (heart rate, blood pressure (NIBP), oxygen saturation $\left(\mathrm{SPO}_{2}\right)$, and electrocardiography (ECG)) were measured and recorded. Intravenous access was secured with a wide bore cannula $(16 \mathrm{G})$ through which normal saline $10 \mathrm{ml} / \mathrm{kg}$ was given for preload over 15 - 20 minutes.

The penile length was measured along the dorsum of the penis from the root as the distance between the penopubic skin junction and urethral meatus in both the flaccid and the post-spinal anaesthesia states of the penis. The penile length was determined in centimeters from the penopubic junction to the urethral meatus by placing the end of a straight-edge tape measure gently against the pubic ramus and without applying traction along the length of the phallus.

The patient was later placed in the sitting position with support from an assistant. Aseptic technique was observed, the researcher was gowned and gloved, and the skin of the patient's back was cleaned with povidone iodine and draped. The area of puncture $\left(\mathrm{L}_{3} / \mathrm{L}_{4}\right.$ interspace) was infiltrated with $3 \mathrm{ml}$ of $1 \%$ plain lidocaine. Using a sise introducer, subarachnoid block was performed with a 26 gauge pencil point spinal needle. The needle was advanced until a 'give' was felt.

Correct placement of the spinal needle in the subarachnoid space was confirmed by a free -flow of the cerebrospinal fluid on withdrawal of the stylet. All the patients received heavy bupivacaine $0.5 \% \quad 10 \mathrm{mg}(2 \mathrm{ml})$ as the local anaesthetic agent for the subarachnoid block. The needle was withdrawn and light sterile dressing placed over the puncture site. Each patient was then placed in the supine position while ensuring and maintaining a 5-10 degree head up tilt.

While the patient's vital signs were checked and recorded every $2 \mathrm{~min}$ for the first $10 \mathrm{~min}$ after institution of spinal anaesthesia and thereafter every $5 \mathrm{~min}$ till end of surgery. Following the administration of spinal anaesthesia, the penis was repeatedly measured every 5 min until the $20^{\text {th }}$ min until the maximal change in length was obtained and recorded. The maximal height of block was determined while the intensity of motor block was assessed using the modified Bromage Score as modified by Breen et al [3]:

BI - Complete block (unable to move feet and knees)

B2 - Almost complete block (able to move feet only)
B3 - Partial block (just able to move knees)

B4 - Detectable weakness of hip joint (between scores 3 and 5)

B5 - No detectable weakness of hip flexion while supine (full flexion of knees)

B6 - Able to perform partial knee bend)

No other form of analgesia was administered intraoperatively. Hypotension was regarded as a $20 \%$ fall in baseline blood pressure and treated with intravenous fluid and/or intravenous ephedrine. In case of inadequate anaesthesia as observed by a block height of less than $\mathrm{T}_{10}$, Bromage score of $\mathrm{B} 3$ or more or complaint of pain by the patient 15 min after $\mathrm{SAB}$, patient received general anaesthesia and was excluded from the study.

The statistical analyses were performed by SPSS for Windows 20.0 (SPSS Inc., Chicago, IL, USA). Data were presented as mean \pm SD. Results were evaluated using descriptive statistics, differential t-test for continuous variables and a Pearson's correlation analysis two-tailed Pearson's correlation coefficient, or r). A P-value of less than 0.05 was used as a threshold for statistical significance.

\section{Results}

Fifty consecutive male patients scheduled for urosurgical and non-urosurgical procedures were recruited into the study. Only $43(86 \%)$ participated throughout the study. Seven (14\%) patients were excluded from the study due to conversion either into general anaesthesia due to inadequate analgesia from the administered subarachnoid block or received additional agents to augment the spinal anaesthesia.

Table 1 shows the demographic data of the patients. The age of the patients ranged from $19-78$ (median 60) years with the mean age $57.7 \pm 13.9$ years. Of the patients that participated in the study, only $11.6 \%$ of them did not have any formal education. While $53.5 \%$ of the patients were ASA I, $39.5 \%$ and $7.0 \%$ of them were ASA II and III respectively.

Table 1. Demographic data.

\begin{tabular}{lll}
\hline Variable & Number & Percent (\%) \\
\hline Mean age (years) & $* 57.7 \pm 13.9$ & \\
Level of Education & & \\
Tertiary & 11 & 25.6 \\
Secondary & 18 & 41.9 \\
Primary & 9 & 20.9 \\
No formal & 5 & 11.6 \\
ASA Class & & \\
I & 23 & 53.5 \\
II & 17 & 39.5 \\
III & 3 & 7.0 \\
\hline
\end{tabular}

$*$ Mean \pm SD.

Table 2 shows the indications for surgery. It shows that benign prostatic hyperplasia constituted about $41.9 \%$ of the indications for surgery while urethral stricture, bladder neck stenosis, prostatic cancer and cystitis made up $20.9 \%, 11.6 \%$, $7.0 \%$ and $4.7 \%$ respectively. Other indications such as hernia, scrotal lipoma, bladder cancer, bladder stone and testicular torsion each contributed $2.3 \%$ of the indication for surgery. 
Table 2. Indications for surgery.

\begin{tabular}{lll}
\hline Indication & Number & Percent (\%) \\
\hline Benign Prostate Hyperplasia & 18 & 41.9 \\
Urethral stricture & 9 & 20.9 \\
Cancer of prostate & 3 & 7.0 \\
Cystitis & 2 & 4.7 \\
Bladder neck stenosis & 5 & 11.6 \\
Hernia & 1 & 2.3 \\
Scrotal lipoma & 1 & 2.3 \\
Bladder cancer & 1 & 2.3 \\
Testicular torsion & 1 & 2.3 \\
Bladder stone & 1 & 2.3 \\
Varicocoele & 1 & 2.3 \\
\hline
\end{tabular}

Table 3 shows the block characteristics and the mean haemodynamic variables. The maximal height of motor block was $\mathrm{T}_{10}$ while the maximal attained motor block was modified Bromage B1. The mean systolic, diastolic and mean arterial blood pressures were $128 \pm 15 \mathrm{mmHg}, 60 \pm 23 \mathrm{mmHg}$ and $75 \pm 18$
$\mathrm{mmHg}$ respectively. The mean $\mathrm{SPO}_{2}$ was $97 \pm 1.24 \%$.

Table 3. Block characteristics and mean haemodynamic variables.

\begin{tabular}{ll}
\hline Maximal height of block & $\mathbf{T}_{\mathbf{1 0}}$ \\
\hline Maximal modified Bromage score* & $\mathrm{B} 1$ \\
Mean $\mathrm{SPO}_{2}(\%)$ & $97 \pm 1.24$ \\
Mean Systolic blood pressure $(\mathrm{mmHg})$ & $128 \pm 15$ \\
Mean Diastolic blood pressure $(\mathrm{mmHg})$ & $60 \pm 23$ \\
Mean mean arterial blood pressure $(\mathrm{mmHg})$ & $75 \pm 18$ \\
\hline
\end{tabular}

*Modified Bromage score by Breen et $\mathrm{al}^{2}$.

Table 4 shows the change in penile length during tumescence. While the mean initial penile length was $12.1 \pm 0.53 \mathrm{~cm}$ and the mean final length was $15.7 \pm 0.53 \mathrm{~cm}$, the mean maximal change in penile length was $3.6 \pm 1.5 \mathrm{~cm} ; \mathrm{p}<0.0001$. There was no statistical correlation between age and mean differential change in length of penis $(r=-0.2842, p=0.43)$.

Table 4. Preanaesthetic and post anaesthetic penile length.

\begin{tabular}{|c|c|c|c|c|c|c|c|}
\hline $\mathbf{S} / \mathbf{N}$ & Age & Indication & Surgery & Initial length (cm) & Final length (cm) & $\begin{array}{l}\text { Difference in length } \\
(\mathrm{cm})\end{array}$ & $\begin{array}{l}\text { Percentage }(\%) \\
\text { increase }\end{array}$ \\
\hline 1 & 65 & $\mathrm{BPH}$ & Open prostatectomy & 13.9 & 14.3 & 0.4 & 2.9 \\
\hline 2 & 72 & $\mathrm{BPH}$ & Open prostatectomy & 11.3 & 16.1 & 4.8 & 42.5 \\
\hline 3 & 68 & $\mathrm{BPH}$ & Open prostatectomy & 12.0 & 14.0 & 2.0 & 16.7 \\
\hline 4 & 70 & $\mathrm{BPH}$ & Open prostatectomy & 11.8 & 19.0 & 7.2 & 61.0 \\
\hline 5 & 64 & $\mathrm{BPH}$ & Open prostatectomy & 13.2 & 16.4 & 3.2 & 24.2 \\
\hline 6 & 70 & $\mathrm{BPH}$ & Open prostatectomy & 10.9 & 14.0 & 3.1 & 28.4 \\
\hline 7 & 69 & $\mathrm{BPH}$ & Open prostatectomy & 12.2 & 16.5 & 4.3 & 35.3 \\
\hline 8 & 60 & $\mathrm{BPH}$ & Open prostatectomy & 11.0 & 15.5 & 4.5 & 40.9 \\
\hline 9 & 72 & $\mathrm{BPH}$ & Open prostatectomy & 16.5 & 18.0 & 1.5 & 9.1 \\
\hline 10 & 49 & $\mathrm{BPH}$ & Open prostatectomy & 10.5 & 15.6 & 5.1 & 48.6 \\
\hline 11 & 72 & $\mathrm{BPH}$ & Open prostatectomy & 14.0 & 17.2 & 3.2 & 20.0 \\
\hline 12 & 65 & $\mathrm{BPH}$ & Open prostatectomy & 15.0 & 18.0 & 3.0 & 18.6 \\
\hline 13 & 64 & $\mathrm{BPH}$ & Open prostatectomy & 16.0 & 19.0 & 3.0 & 18.8 \\
\hline 14 & 65 & $\mathrm{BPH}$ & Open prostatectomy & 11.0 & 17.5 & 6.5 & 50.1 \\
\hline 15 & 71 & $\mathrm{BPH}$ & Open prostatectomy & 9.0 & 16.0 & 7.0 & 77.8 \\
\hline 16 & 55 & $\mathrm{BPH}$ & Open prostatectomy & 12.0 & 16.0 & 4.0 & 33.3 \\
\hline 17 & 58 & $\mathrm{BPH}$ & TURP & 13.2 & 16.0 & 2.8 & 21.2 \\
\hline 18 & 56 & $\mathrm{BPH}$ & TURP & 11.5 & 12.5 & 1.0 & 8.7 \\
\hline 19 & 34 & Urethral stricture & Urethroplasty & 12.6 & 15.5 & 2.9 & 23.0 \\
\hline 20 & 60 & Urethral stricture & Urethroplasty & 8.9 & 14.3 & 5.4 & 60.7 \\
\hline 21 & 55 & Urethral stricture & Urethroplasty & 14.0 & 18.2 & 4.2 & 30.0 \\
\hline 22 & 38 & Urethral stricture & Urethroplasty & 11.8 & 15.5 & 3.7 & 31.4 \\
\hline 23 & 65 & Urethral stricture & Urethroplasty & 13.0 & 15.1 & 2.1 & 16.2 \\
\hline 24 & 27 & Urethral stricture & Urethroplasty & 11.5 & 14.5 & 3.0 & 26.1 \\
\hline 25 & 51 & Urethral stricture & Urethrotomy & 11.0 & 14.5 & 3.5 & 31.8 \\
\hline 26 & 52 & Urethral stricture & Urethrotomy & 9.7 & 12.5 & 2.8 & 28.9 \\
\hline 27 & 46 & Urethral stricture & Urethrotomy & 12.6 & 16.1 & 3.5 & 27.8 \\
\hline 28 & 60 & Bladder neck stenosis & TUIP & 15.5 & 19.0 & 3.5 & 22.6 \\
\hline 29 & 76 & Bladder neck stenosis & Urethrotomy & 11.5 & 17.2 & 5.7 & 49.6 \\
\hline 30 & 73 & Bladder neck stenosis & Urethrotomy & 12.0 & 14.1 & 2.1 & 17.5 \\
\hline 31 & 51 & Bladder neck stenosis & Urethrotomy & 13.0 & 17.0 & 4.0 & 30.8 \\
\hline 32 & 67 & Bladder neck stenosis & Urethrotomy & 12.0 & 15.0 & 3.0 & 25.0 \\
\hline 33 & 37 & Cystitis & Cystoscopy & 11.0 & 12.4 & 1.4 & 12.7 \\
\hline 34 & 46 & Cystitis & Cystoscopy & 9.7 & 13.0 & 3.3 & 34.0 \\
\hline 35 & 73 & Prostate cancer & Cystoscopy & 10.5 & 16.0 & 5.5 & 52.4 \\
\hline 36 & 78 & Prostate cancer & TURP & 12.5 & 15.6 & 3.1 & 24.8 \\
\hline 37 & 69 & Prostate cancer & TURP & 11.0 & 15.8 & 4.8 & 43.6 \\
\hline 38 & 52 & Bladder cancer & Cystoscopy & 13.7 & 16.5 & 2.8 & 20.4 \\
\hline 39 & 44 & Bladder stone & Lithocystotomy & 11.6 & 14.5 & 2.9 & 25.0 \\
\hline 40 & 19 & Testicular torsion & Orchidopexy & 10.4 & 14.0 & 3.6 & 34.6 \\
\hline 41 & 36 & Varicocoele & Bilateral varicocoele ctomy & 12.0 & 17.5 & 5.5 & 45.8 \\
\hline 42 & 50 & Left inguinal hernia & Herniorrhaphy & 10.5 & 15.6 & 5.1 & 48.6 \\
\hline 43 & 56 & Scrotal lipoma & Excision & 11.0 & 15.8 & 4.8 & 43.6 \\
\hline
\end{tabular}




\section{Discussion}

This study showed that an administered spinal anaesthetic could produce a reversible increase in length of the penis. The study also showed that there was no statistical correlation between the change in length and age of the patient. The tumescence observed was not also related to the type of urologic surgery.

Tumescence during urosurgical procedures have been extensively studied however, but no study has measured the change in length that occurs under regional anaesthesia. Flaccid penile length has been compared in relation to body mass index, shoe size, height, weight, waist/hip ratio. $[4,5]$ in these studies a positive correlation was found between penile length (flaccid and erect) and somatometric parameters. Although in our study, the change in length observed under spinal anaesthesia was not compared to the somatometric parameters of our patients, the effect of the anaesthesia could influence the testicular volume. The testicular volume change could not be assessed as our centre does not have a Prader orchidometer.

Penile erection is a complex but coordinated phenomenon produced by a combination of vascular, nervous and psychogenic factors. Both sympathetic neurons in the thoracolumbar cord and parasympathetic neurons in the sacral cord regulate the blood flow to corpus cavernosum which in turn leads to either flaccidity or tumescence of penis.

The intraoperative erection could be due to a product of massive blood flow into the penis following the sympathetic effect of the local anaesthesia administered into the subarachnoid space. It is very possible that local stimulation following the handling of the phallus during measurements prior to the administration of spinal anaesthesia could also lead to stimulation. The effect of this stimulation could contribute to the initiation of the erection process. However, whether the penis was handled or not, the increase in both volume and length could still occur. This finding corroborates with that of Lue et al. [6] Although the intraoperative erection could occur even in patients undergoing general anaesthesia following preoperative catheterization, this was also observed in the patients excluded from our study.

However, penile erection under spinal and epidural anaesthesia is reflexogenic, especially if the sympathetic blockade extends above the mid-thoracic level or it could be both reflexogenic and psychogenic. [7, 8] The reflexogenic stimuli arise due to stimulation of the pudendal nerve $\left(\mathrm{S}_{2}, \mathrm{~S}_{3}\right.$, and $\mathrm{S}_{4}$ ) with instrumentation such as catheterization before onset of complete sensory blockade. Another possible explanation is incomplete blockade of sacral segments of the spinal cord during spinal anaesthesia. All the patients in our study received the same dose of $0.5 \%$ heavy bupivacaine. The effect of differential doses of subarachnoid bupivacaine is yet to be determined but could be an area for further study.

The mechanism of tumescence during spinal anaesthesia is a very complex phenomenon. In the flaccid state, the penile arterioles are partially opened, while the venules and the arteriovenous channels remain open, hence providing an unimpeded drainage of the arterial inflow. [9] The application of local anaesthetic agent in the subarachnoid space will block sympathetic output and increase sacral parasympathetic outflow, causing relaxation of the corporal arterioles and partial closure of the venules and arteriovenous shunts with subsequent engorgement of the corpora leading to erection. [10, 11] the effects of the sympathetic and parasympathetic nervous system on the male sexual organ are well known to be complementary. The activation of the $\mathrm{M}_{3}$ cholinergic receptor type will give rise to penile tumescence or erection.

Normally the erection subsides after sympathetically mediated arteriolar constriction with the reduction of inflow and enhanced venous drainage.[5] Detumescence during spinal anaesthesia occurs with the onset of regression time of sensorimotor block and, it is mediated by the return of sympathetic activity that causes a constriction of penile venous sinusoids, opening emissary veins and thereby increasing blood drainage. This could explain why the detumescence observed occurred as the effect of the spinal anaesthesia began to wane. Although our study did not compare the rate of detumescence per unit time with the regression time of the spinal anaesthesia, the penile length progressively returned to its pre-spinal anaesthesia (flaccid) length.

Penile tumescence could pose a huge challenge during some urologic surgeries. This challenge should be weighted between operating on ill-patient facing the challenges of general anaesthesia and a conscious patient with the option of better recovery profile and earlier discharge from the hospital. Although many pharmacologic agents $[12,13,14]$ have been used to treat tumescence that arises from the effect of anaesthesia, the attending surgeon should properly evaluate the patient for co-morbidities and agent (s) used as some of these medications could have deleterious effect.

Spinal anaesthesia, though having some advantages such as reducing blood loss in urologic surgeries [15], is also well known to be associated with certain cardiovascular and respiratory side effects. In our study all the patients received the same dose (volume) of heavy bupivacaine although with different surgical indications. The change in the penile length could not have been due to the volume of spinal anaesthetic injected. No deteriorations of haemodynamic stability or significant postoperative complications were observed in our patients. Whenever these minor complications occurred, they were not at such a level that required any form of intervention. However, mild hypotension that occurred in some patients was treated with rapid fluid administration.

\section{Conclusion}

The study shows that regional anaesthesia causes tumescence and the change in length was found to be 
statistically significant. While the reversible differential change in length did not correlate with the age of the patient, it could significantly impact on some urologic surgeries that require the penis in flaccid state.

\section{Conflict of Interest}

The authors declare that they have no competing interests.

\section{References}

[1] Van Arsdalen KN, Chen JW, Smith MJ. Penile erections complicating transurethral surgery. J Urol 1983; 12: 374-376.

[2] Nates WA. Penile erection complicating transurethral surgery. SAJAA 2007; 13:2, 53, DOI: 10. 1080/22201173. 2007. 10872478.

[3] Breen TW, Shapiro T, Glass B, Foster-Payne D, Oriel NE. Epidural anaesthesia for labor in an ambulatory patient. Anesth Analg 1993; 77: 919-924.

[4] Shah J, Christopher N. Can shoe size predict penile length? BJU Int 2002; 90: 586--587.

[5] Spyropoulos E, Borousas D, Mavrikos S, Dellis A, Bourounis M, Athanasiadis S. Size of external genital organs and somatometric parameters among physically normal men younger than 40 years old. Urology 2002; 60: 485-489.

[6] Lue TF, Zeineh SJ, Schmidt RA, Tanagho EA. Neuroanatomy of penile erection: its relevance to iatrogenic impotence. J Urol 1984; 131: 273-280.
[7] Shantha TR. Intraoperative management of penile erection by using terbutaline. Anesthesiology 1989; 70: 707-709.

[8] Robert SW, Jay BB. Treatment of intraoperative penile tumescence. J Urol 1980; 124: 925.

[9] Baltogiannis DM, Charalabopoulos AK, Giannakopoulos XK, Giannakis DJ, Sofikitis NV, Charalabopoulos KA. Penile erection during transurethral surgery. J Androl 2006; 27: 376380 .

[10] Rao TH, Zaman W, Jain RK. Intraoperative penile erection. Arch Esp Urol. 2000; 53: 953-956.

[11] Walther PJ, Meyer AF, Woodworth BE. Intraoperative management of penile erection with intracorporeal phenylephrine during endoscopic surgery. J Urol 1987; 137: 738-739.

[12] De Meyer JM, De Sy WA. Intracavernous injection of noradrenaline to interrupt erections during surgical interventions. Eur Urol 1986; 12: 169-170.

[13] Seftel AD, Resnick MI, Boswell MV. Dorsal nerve block for the management of intraoperative penile erection. J Urol 1994 151: 394-395.

[14] Valley MA, Sang CN. Use of glycopyrrolate to treat intraoperative penile erection: case report and review of the literature. Reg Anaesth 1994; 19: 423-428.

[15] Fyneface-Ogan S, Eke N. Intraoperative blood loss during retropubic Prostatectomy: a comparison of regional and general anaesthesia. J Coll Med 2004; 9: 8-11. 